\title{
Weight Change and Its Predictors among Newly Initiated ART Clients in Dessie City, Northeast Ethiopia, July 2020. Longitudinal Data Analysis
}

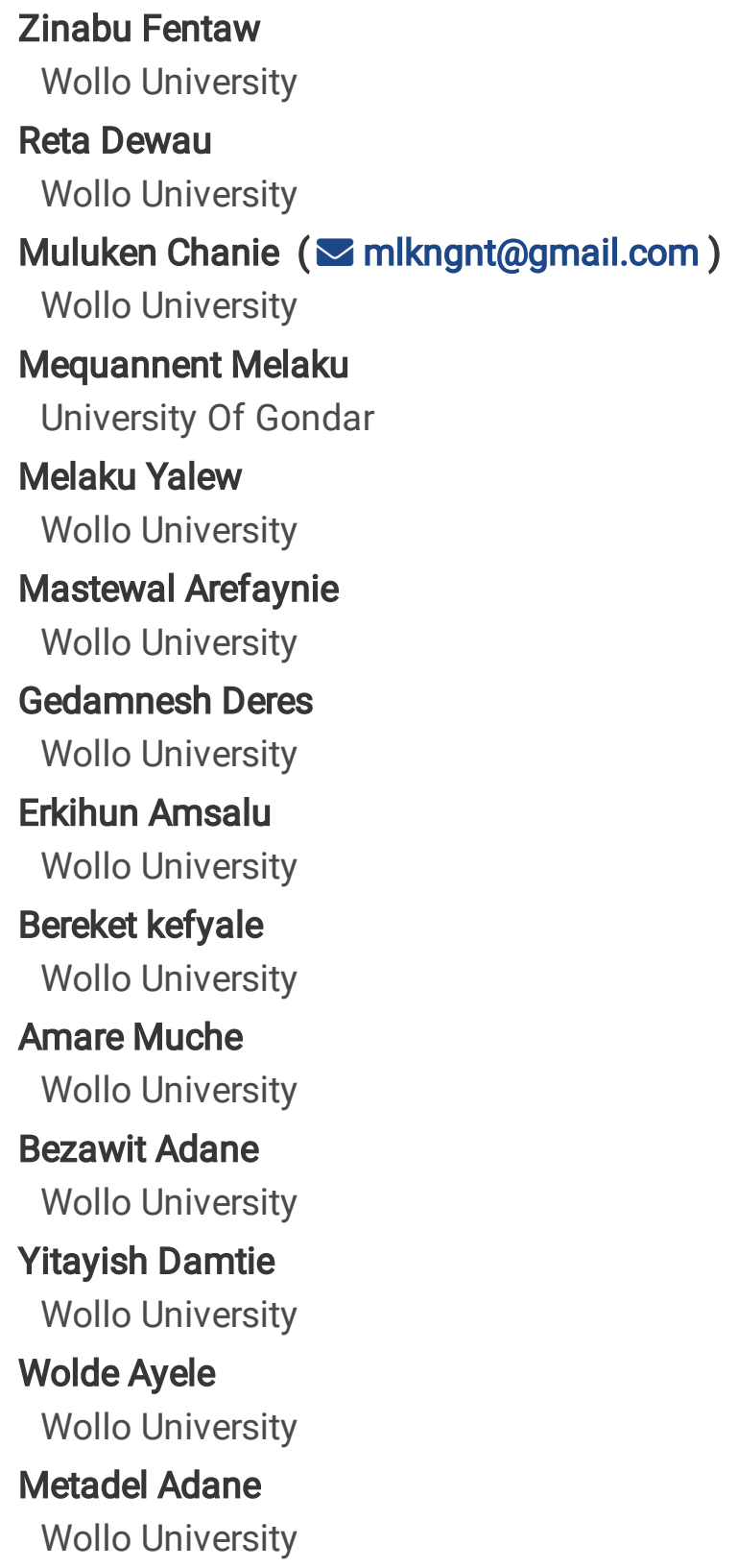

\section{Research Article}

Keywords: HIV/AIDS, Antiretroviral Therapy, Weight, Longitudinal Data Analysis, MANOVA 
DOI: https://doi.org/10.21203/rs.3.rs-118721/v1

License: (c) (1) This work is licensed under a Creative Commons Attribution 4.0 International License. Read Full License 


\section{Abstract \\ Background}

The weight of HIV/AIDS patients is one of the classifications WHO clinical staging of the diseases. A positive weight change in antiretroviral therapy patients is one of the expected clinical outcomes within a few months after the initiation of antiretroviral therapy in previously naïve patients. But the weight change varies across clients, and the reason for this variation and the effect of time-varying clinical profiles on the weight of the clients is not well investigated.

\section{Method:}

A retrospective cohort study was conducted in Dessie City Health Facility in July 2020. The data were collected using a simple random sampling method in adult antiretroviral therapy clients who were enrolled to care between January to June 2019. Totally, 58 charts were reviewed within three months interval for 6 consecutive observations per chart. The data were entered into Epi-data, and analyzed using Stata 14. The effect of Panel and random effect model was assessed using Breusch and Pagan and Hausman's test, respectively. Finally, the Random Effect Generalize Least Square model was fitted, and variables with a p-value less than 0.05 were considered as the predictors of weight change.

\section{Result}

A total of 58 clients chart with 322 observations were assessed and the mean age (standard deviation) of participants were $37(10)$ and $30(51.7 \%)$ of them were female clients. The absence of opportunistic infection ( $\beta: 1.85 ; 95 \%$ Cl:0.66-3.03) the interaction of opportunistic infection and months on Antiretroviral Therapy ( $\beta: 0.09$; $95 \% \mathrm{Cl}: 0.05-0.13)$ and advanced WHO clinical stage ( $\beta$ : $-3.52 ; 95 \% \mathrm{Cl}$ : $-6.71-(-0.34))$ were significantly associated with the weight of adult Antiretroviral Therapy user overtime.

\section{Conclusion}

There is a significant positive weight change after imitation of Antiretroviral Therapy. The absence of opportunistic infection and its interaction with time have a positive change on the weight of adult Antiretroviral Therapy clients whereas, experiencing advanced WHO stage disease over time has a negative effect on the weight change.

\section{Introduction}

HIV infection and undernutrition are mainly affecting Sub-Sahara African Countries including Ethiopia(1). Weight of the patient is one of the most affected clinical parameters and an indicative measurement for treatment response. Moreover, it is an important indicator for the classification of WHO clinical stage of the disease, which lies from unexplained weight loss in stage II into a severe wasting syndrome in stage IV(2).

A positive weight change among clients on antiretroviral therapy (ART) is one of the expected clinical outcomes within a few months after the initiation of ART in ART naïve patients (3). Most ART clients in Ethiopia are underweight(4), and a positive weight change shows a major indicator for clinical progress and one of the signs of 
gaining adequate nutrition(5). Weight of adult ART users attain the maximum weight within one year, and almost all adults' height keeps constant (6). Low baseline body weight is one of the main risks of death in naïve ART clients, and also early weight gain improves ART outcomes $(1,7)$. Weight loss is one of an acute response for inadequate intake of nutrients, which induces a low immune response(5). The low immune response increases the diseases incidence severity and prolongs the duration of the diseases as well a poor weight gain is a potential sign of treatment failure(2). Low body mass index (BMI) decrease adherence status of patients to Antiretroviral (ARV) drugs(8).

So, taking a drug in previous naïve patients will expected a change in weight over time, as well as the interaction between weight and covariates, have a contribution to a change in weight in each patient(9). The weight change varies across clients some of them decrease, the other stagnant change and some others sharply increase, and the factor for this variation is not well investigated. ART providers measure the weight of their clients every month as a prognostic indicator and clinical compliance of ART drug, but there is no sufficient evidence on the effect of timevariant clinical profiles and sequence of events for the contribution of weight change with its degree and directions(10). This study tries to assess the change of weight and determinant clinical profiles in Adult ART clients.

\section{Methods And Materials}

\section{Study Area, Period and Study Design}

A retrospective cohort study was conducted in Dessie City Health Facility, which is 401 km away from Addis Ababa a capital city of Ethiopia. Overall, 514 clients started ART from January to June 2019. Based on the national modality of ART health service delivery, a newly ART initiated clients should visit the facility every month for one year and then may adopt to three or six months follow up a schedule following the client's health status and willingness(11). During their visit, clients were measured their clinical condition and recorded to ART follow up form then data stored into Smart care database(12).

\section{Population}

All adult ART users, who were taking ART drugs for the first time from January 2019 to June 2019, were considered as source populations. Clients, who were attending at least three or more follow-ups, were included in the study.

\section{Exclusion Criteria}

Pregnant women, who were initiated ART between January to June 2019 and being pregnant from initiation to July 2020, were excluded from the study.

Variables

Predicted Variable: consecutive measured weight

\section{Predictor Variable}

Socio-demographic factors: age, sex, marital status, Educational status, occupation,

Baseline clinical Profile: CD4 count, WHO stage, Co-morbid illness, OI, ART drugs regimen, CPT, IPT, and ADR report. Food by prescription, 
Three months follow up change on: regimen change: CPT status: CPT adherence, ARV adherence, Viral load measurement, Ol, Clinical (T-stage), food by prescription.

\section{Sample Size Determination}

The sample size of this study was determined by standard longitudinal continuous variable outcomes, through the assumption that the number of subjects in each group is equal with a $95 \%$ level of Confidence and $80 \%$ of power(13).

$\mathrm{N}=\frac{\left(Z_{\left(1-\frac{\alpha}{2}\right)}+Z_{(1-\beta)}\right)^{2} * \delta^{2} *(r+1) *[1+(T-1) \rho]}{T * V^{2}}$

Where $\mathrm{N}=$ the total sample size $Z_{\left(1-\frac{\alpha}{2}\right)}=$ is $\left(1-\frac{\alpha}{2}\right)$ the distribution of $\mathrm{z}$ table andZ(1-\&beta; $)$ is the normal distribution of the power $\delta^{2}$ is the variance of outcome variable and T is the number of observations $\rho=$ is correlation coefficient in outcome variable and $\mathrm{V}^{2}=$ is the mean deference in Advanced WHO stage and WHO early stage of the diseases at baseline.

Since there is a limited longitudinal study for the weight of Adult ART clients, a preliminary survey was conducted in the study area among 20 Adult ART clients for six observations. The sample size was calculated using the computed mean weight of early and advanced WHO Stage diseases, the standard deviation of weights, and the correlation coefficient of the weight of patients. Finally, the calculated sample size was 58 adult ART clients were eligible for the study with a maximum of six and a minimum of three observations.

$\mathrm{N}=\frac{\left(Z_{\left(1-\frac{\alpha}{2}\right)}+Z_{(1-\beta)}\right)^{2 * \delta^{2} *(r+1) *[1+(T-1) \rho]}}{T * V^{2}} \mathrm{~N}=\frac{7.85 * 7.65 *(1+1) *[1+(6-1) 0.27]}{6 * 0.9^{2}}$

$\mathrm{N}=\frac{7.85 * 7.65 *(2) *[1+(5) 0.27]}{6 * 0.81}=58$

\section{Sampling Procedure}

The total number of newly enrolled clients between January and June 2019 was 514. Among the newly enrolled clients in the study period, 421 and 93 were having three or more and less than three follow up, respectively. Regarding the availability of necessary data 338 and 81 charts were complete and incomplete, respectively. During preparing the chart for data collection, 25 Charts were lost and 313 of the completed charts were availed for data collection. All the 313 clients' medical record numbers were listed and using simple random sampling technique 58 of them were select randomly through the lottery method.

\section{Data collection Procedure}


The data were extracted from the patient follow up chart and ART register in July, 2020. The checklist was developed from ART Guideline, ART register, and ART follow up forms. The baseline weight of the patients was taken at a follow-up chart, and other sociodemographic and clinical profiles were also taken at the same time.

\section{Data Quality Control}

The data were entered into epi-data version 3.1 and exported to Stata version 14.0. The data were entered by double data entry and check the consistency between the two data entry through double-checking and the exactness of missing data and only a few data were found inconsistent and managed through the verification of data from the extraction sheet.

\section{Data Analysis Procedures}

Data were described with mean and standard deviation and frequency present with table and percentage. To detect the variation of repeat measure of weight, a repeated measure of ANOVA regression was computed. The panel data were tested through Breusch and Pagan Lagrangian multiplier test for the effects panel, which results statistically significant. The Hausman's post estimation also tested for the effect of Random Effect Model, which results nonsignificant then the final model was fitted to Random-effects Generalize Least Square regression.

\section{Ethical Issue}

The ethical issue was secured from Wollo University College of Medicine and Health Science Ethical Review Committee and permission letters also were obtained from Dessie City Zonal Health Department and respective health facilities and all methods were performed in accordance with Helsinki Declaration. The information provided in each chart of adult ART clients was kept strictly confidential.

\section{Result}

\section{Sociodemographic Characteristics}

A total of 58 adult HIV patient medical charts were assessed with their repeated follow up for about 322 observations. The mean age (SD) was 37 (10) years with a minimum of 19 years and a maximum of 61 years old. Around 30 (51.7\%) of them were female and, 24(41.4\%) of them were also married. Regarding educational status and residence 25 (43\%) and 39 (67.2\%) were primary school level and urban dwellers, respectively. More than half $33(56.9 \%)$ of them does not disclose their HIV status to their families and relatives (Table 1). 
Table 1

Sociodemographic Characteristics of Adult Newly ART initiated Clients in Dessie City, July 2020 $\left(n=58, T^{a}=6\right.$ and number of Observations 322).

\begin{tabular}{|c|c|c|c|c|c|c|c|}
\hline \multirow[t]{2}{*}{ Variable } & \multirow[t]{2}{*}{ Category } & \multicolumn{6}{|c|}{ Number of Follow up in months } \\
\hline & & 0 & 3 & 6 & 9 & 12 & 15 \\
\hline \multirow[t]{2}{*}{ Sex } & Male & $28(48.28 \%)$ & $28(48.28 \%)$ & $28(48.28 \%)$ & $26(51.0 \%)$ & $26(51.0 \%)$ & $22(46.8 \%)$ \\
\hline & Female & $30(51.72 \%)$ & $30(51.72 \%)$ & $30(51.72 \%)$ & $25(49.0 \%)$ & $25(49.0 \%)$ & $25(53.2 \%)$ \\
\hline \multirow{4}{*}{$\begin{array}{l}\text { Marital } \\
\text { Status }\end{array}$} & Single & $11(18.97 \%)$ & $11(18.97 \%)$ & $11(18.97 \%)$ & $9(17.6 \%)$ & $9(17.6 \%)$ & $8(17.0 \%)$ \\
\hline & Married & $24(41.38 \%)$ & $2441.38 \%)$ & $2441.38 \%)$ & $22(43.1 \%)$ & $22(43.1 \%)$ & $20(42.6 \%)$ \\
\hline & Divorced & $16(27.59 \%)$ & $16(27.59 \%)$ & $16(27.59 \%)$ & $14(27.5 \%)$ & $14(27.5 \%)$ & $14(29.8 \%)$ \\
\hline & Widowed & $7(12.07 \%)$ & $7(12.07 \%)$ & $7(12.07 \%)$ & $6(11.8 \%)$ & $6(11.8 \%)$ & $6(10.6 \%)$ \\
\hline \multirow[t]{3}{*}{$\begin{array}{l}\text { Educational } \\
\text { Status }\end{array}$} & $\begin{array}{l}\text { No } \\
\text { Education }\end{array}$ & $19(32.76 \%)$ & $19(32.76 \%)$ & $19(32.76 \%)$ & $16(31.4 \%)$ & $16(31.4 \%)$ & $13(27.7 \%)$ \\
\hline & Primary & $25(43.10 \%)$ & $25(43.10 \%)$ & $25(43.10 \%)$ & $24(47.0 \%)$ & $24(47.0 \%)$ & $24(51.0 \%)$ \\
\hline & $\begin{array}{l}\text { Secondary } \\
\text { and above }\end{array}$ & $14(24.14 \%)$ & $14(24.14 \%)$ & $14(24.14 \%)$ & $11(21.6 \%)$ & $11(21.6 \%)$ & $9(21.3 \%)$ \\
\hline \multirow[t]{2}{*}{ Residence } & Urban & $39(67.24 \%)$ & $38(65.52)$ & $39(67.28)$ & $35(68.6 \%)$ & $35(68.6 \%)$ & $32(68.1 \%)$ \\
\hline & Rural & 19(32.76\%) & $20(34.48)$ & 19(32.72) & $16(31.4 \%)$ & $16(31.4 \%)$ & $15(31.9 \%)$ \\
\hline \multirow{2}{*}{$\begin{array}{l}\text { Disclosing } \\
\text { HIV status }\end{array}$} & Yes & $25(43.1 \%)$ & $25(43.1 \%)$ & $26(44.8 \%)$ & $20(39.2 \%)$ & $22(43.1 \%)$ & $21(44.7 \%)$ \\
\hline & No & $33(56.9 \%)$ & $33(56.9 \%)$ & $32(55.2)$ & $31(60.8 \%)$ & $29(56.9 \%)$ & $26(55.3 \%)$ \\
\hline \multirow{4}{*}{$\begin{array}{l}\text { Marital } \\
\text { status }\end{array}$} & Single & $11(19 \%)$ & $11(19 \%)$ & $11(19 \%)$ & $9(17.6 \%)$ & $9(17.6 \%)$ & $8(17 \%)$ \\
\hline & Married & $24(41.4 \%)$ & $24(41.4 \%)$ & $24(41.4 \%)$ & $22(43.1 \%)$ & $22(43.1 \%)$ & $20(42.6 \%)$ \\
\hline & Divorced & $16(27.6 \%)$ & $16(27.6 \%)$ & $16(27.6 \%)$ & $14(27.5 \%)$ & $14(27.5 \%)$ & $14(29.8 \%)$ \\
\hline & Widowed & $7(12 \%)$ & $7(12 \%)$ & $7(12 \%)$ & $6(11.8 \%)$ & $6(11.8 \%)$ & $5(10.6 \%)$ \\
\hline
\end{tabular}

\section{Clinical Profiles}

The clinical profile of clients under antiretroviral drugs varies with time from baseline to month fifteen. The working functional status of ART clients at baseline or at times antiretroviral initiation was $46(79.3 \%)$ and then increases to $46(98 \%)$ at fifteen months from the time initiation. The WHO stage of diseases also favors the same condition, which is $39(67.2 \%)$ stage one at baseline and $46(98 \%)$ in the month fifteen. Most of the clients, 36(62\%) were experienced an opportunistic infection at baseline and decline over to 4(8.5\%) to the end of the follow-up of this study. Most of clients 48(82.8\%) were taking isoniazid as tuberculosis preventive therapy and only a few 3(5.2\%) had TB disease at baseline. In this study, Antiretroviral drug adherence also varies across time the maximum of good adherence 46(90.2\%) was attained at nine-month and the minimum good Antiretroviral drug adherence $39(76.5 \%)$ was at 12 months. Under regimen type half of clients 30(51.7\%) were initiated with DTG based regimen and almost all of them 44(93.6\%) were taking it at the end of the follow-up (Table 2). 
Table 2

Clinical Profile of Newly ART Initiated clients in Dessie City, July 2020(n $=58, T^{\mathrm{a}}=6$ and number of Observations 322).

\begin{tabular}{|c|c|c|c|c|c|c|c|}
\hline \multirow[t]{2}{*}{ Variable } & \multirow[t]{2}{*}{ Category } & \multicolumn{6}{|c|}{ Number of follow up months } \\
\hline & & 0 & 3 & 6 & 9 & 12 & 15 \\
\hline \multirow{2}{*}{$\begin{array}{l}\text { Functional } \\
\text { Status }\end{array}$} & Working & $46(79.3 \%)$ & $54(93.1 \%)$ & $54(93.1 \%)$ & $51(100 \%)$ & $51(100 \%)$ & $46(98 \%)$ \\
\hline & $\begin{array}{l}\text { Ambulatory } \\
\text { and } \\
\text { Bedridden }\end{array}$ & $12(20.7 \%)$ & $4(6.9 \%)$ & $4(6.9 \%)$ & $0(0 \%)$ & $0(0 \%)$ & $1(2 \%)$ \\
\hline \multirow[t]{4}{*}{ WHO Stage } & Stage I & $39(67.2 \%)$ & $39(67.2 \%)$ & $39(67.2 \%)$ & $51(100 \%)$ & $51(100 \%)$ & $46(98 \%)$ \\
\hline & Stage II & $6(10.4 \%)$ & $6(10.4 \%)$ & $6(10.4 \%)$ & $0(0 \%)$ & $0(0 \%)$ & $0(0 \%)$ \\
\hline & Stage III & $10(17.2 \%)$ & $10(17.2 \%)$ & $10(17.2 \%)$ & $0(0 \%)$ & $0(0 \%)$ & $1(2 \%)$ \\
\hline & Stage IV & $3(5.2 \%)$ & $3(5.2 \%)$ & $3(5.2 \%)$ & $0(0 \%)$ & $0(0 \%)$ & $0(0 \%)$ \\
\hline \multirow[t]{2}{*}{ Ol } & Yes & $36(62 \%)$ & $9(15.5 \%)$ & $7(12 \%)$ & $1(2 \%)$ & $5(9.8 \%)$ & $4(8.5 \%)$ \\
\hline & No & $22(38 \%)$ & $49(84.5 \%)$ & $51(88 \%)$ & $50(98 \%)$ & $46(90.2 \%)$ & $43(91.5 \%)$ \\
\hline \multirow[t]{2}{*}{ TB } & Yes & $3(5.2 \%)$ & $3(5.2 \%)$ & $3(5.2 \%)$ & $0(0 \%)$ & $0(0 \%)$ & $0(0 \%)$ \\
\hline & No & $55(94.8)$ & $55(94.8)$ & $55(94.8)$ & $51(100 \%)$ & $51(100 \%)$ & $47(100 \%)$ \\
\hline \multirow[t]{3}{*}{ Adherence } & Good & & $48(82.8 \%)$ & $46(79.3 \%)$ & $46(90.2 \%)$ & $39(76.5 \%)$ & $41(87.2 \%)$ \\
\hline & Fair & & $9(15.5 \%)$ & $7(12 \%)$ & $4(7.84 \%)$ & $8(15.7 \%)$ & $4(8.5 \%)$ \\
\hline & Poor & & $1(1.7 \%)$ & $5(8.7 \%)$ & $1(2 \%)$ & $4(7.8 \%)$ & $2(4.3 \%)$ \\
\hline \multirow{2}{*}{$\begin{array}{l}\text { Regimen } \\
\text { category }\end{array}$} & DTG based & $30(51.7 \%)$ & $32(55.2 \%)$ & $34(57.9 \%)$ & $39(76.5 \%)$ & $39(86.3 \%)$ & $44(93.6 \%)$ \\
\hline & NVP/EFV & $28(48.3 \%)$ & $26(44.8 \%)$ & $24(42.1 \%)$ & $12(23.5 \%)$ & $12(13.7 \%)$ & $3(6.4 \%)$ \\
\hline \multirow{2}{*}{$\begin{array}{l}\text { Taking Other } \\
\text { Medication }\end{array}$} & Yes & $38(65.5 \%)$ & $10(17.2 \%)$ & $8(12.3 \%)$ & $2(3.9 \%)$ & $3(5.9 \%)$ & $3(6.4 \%)$ \\
\hline & No & $20(34.5 \%)$ & $48(82.8 \%)$ & $50(87.7 \%)$ & $49(96.1 \%)$ & $48(94.1 \%)$ & $44(93.6 \%)$ \\
\hline \multirow{2}{*}{$\begin{array}{l}\text { Modern } \\
\text { Family } \\
\text { Planning }\end{array}$} & Yes & $35(60.3 \%)$ & $36(62.1 \%)$ & $37(63.8 \%)$ & $37(72.5 \%)$ & $37(72.5 \%)$ & $37(70.2 \%)$ \\
\hline & No & $23(39.7 \%)$ & $22(37.9 \%)$ & $21(36.2 \%)$ & $14(27.5 \%)$ & $14(27.5 \%)$ & $14(29.8 \%)$ \\
\hline \multirow[t]{2}{*}{$\begin{array}{l}\text { Taking INH } \\
\text { Currently }\end{array}$} & $\begin{array}{l}\text { Currently on } \\
\text { INH }\end{array}$ & $48(82.8 \%)$ & $53(91.4 \%)$ & $53(91.4 \%)$ & $3(5.9 \%)$ & $0(0 \%)$ & $0(0 \%)$ \\
\hline & Not on INH & $10(17.2 \%)$ & $5(8.6 \%)$ & $5(8.6 \%)$ & $48(94.1 \%)$ & $51(100 \%)$ & $47(100 \%)$ \\
\hline \multirow{2}{*}{$\begin{array}{l}\text { Taking CPT } \\
\text { currently }\end{array}$} & Yes & $46(79.3 \%)$ & $42(72.4 \%)$ & $42(72.4 \%)$ & $35(68.6 \%)$ & $34(66.7 \%)$ & $35(74.5 \%)$ \\
\hline & No & $12(20.7 \%)$ & $16(27.6 \%)$ & $16(27.6 \%)$ & $16(31.4 \%)$ & $17(33.3 \%)$ & $12(25.5 \%)$ \\
\hline
\end{tabular}

\section{Summary Measures for Covariates}

The mean weight (SD) vary across time $51.3(8.3) \mathrm{kg}$ at baseline to $55.8(8.4) \mathrm{kg}$ at the end of 15 month on ART and the overall mean (SD) was $54.6(7.86) \mathrm{kg}$. The mean (SD) body mass index at baseline was $19.4(3.3) \mathrm{kg}$ and then 
raise overtime to $21.3(3.25) \mathrm{kg}$ at the end of this follow-up study (Table 3).

Table 3

Summary measures for Covariates in Newly ART initiated in Dessie City, July $2020\left(n=58, T^{a}=6\right.$ and number of Observations 322).

\begin{tabular}{|c|c|c|c|c|c|c|c|c|}
\hline \multirow[t]{2}{*}{ Covariates } & \multirow[t]{2}{*}{ Summary measures } & \multicolumn{6}{|c|}{ Number of follow up months } & \multirow[t]{2}{*}{ Total } \\
\hline & & 0 & 3 & 6 & 9 & 12 & 15 & \\
\hline \multirow[t]{4}{*}{ Weight } & Mean & 51.3 & 53.8 & 54.1 & 56.4 & 56.9 & 55.8 & 54.58 \\
\hline & Standard Deviation & 8.3 & 7.6 & 7.45 & 6.8 & 7.42 & 8.4 & 7.86 \\
\hline & Minimum & 33 & 33.2 & 33 & 45 & 42 & 32 & 32 \\
\hline & Maximum & 72 & 77 & 75 & 80 & 80 & 80 & 80 \\
\hline \multirow[t]{4}{*}{ BMI } & Mean & 19.4 & 20.3 & 20.5 & 21.08 & 21.35 & 21.3 & 20.63 \\
\hline & Standard Deviation & 3.3 & 2.98 & 3.0 & 2.7 & 3.06 & 3.25 & 3.12 \\
\hline & Minimum & 14 & 14 & 14 & 16.8 & 17 & 16 & 14 \\
\hline & Maximum & 30.3 & 30.4 & 31.5 & 29 & 29 & 29 & 31.5 \\
\hline
\end{tabular}

\section{Profile Plotting of Weight against Months on ART}

The weights of ART clients were varying across sex, which is more varies at baseline among females, and also the variation continues over time. Unlike female, the variation in male at baseline lesser and also the variation in male slightly decrease over time (Fig. 1).

Figure 1 Individual Profile of Newly ART initiated ART Clients in Dessie City, July 2020.

The mean weight change shows a quadratic nature (Fig. 2), and there is a difference between males and females. The mean weight among females is lower than male (Fig. 3).

Figure 2 The mean Weight Chane in Dessie City, July 2020.

Figure 3 The mean weight in Male and Female in Dessie City, July 2020

\section{The Weight Changes across Months on ART.}

The Repeated measure of ANOVA with a Wilk's Lamda statistics shows that there is a significant difference in the weight change of adult ART clients with a P-Value $<0.001$. The variations were detected by wild statistics of Bonferroni methods and the result shows a significant difference every six months apart and more rather than within three months interval.

Adult ART clients gain weight $4.92 \mathrm{~kg}$ (C95\%: 3.03-6.82) within one year after the initiation of ART clients. The mean weight changes after initiation of ART over 15 months of follow up is decreased to $3.28 \mathrm{~kg}$. This study address change of weights after initiation of adult ART clients and its covariate predictors. The analysis shows that 
no opportunistic infection, the interaction between months on ART and absence of opportunistic infection, and WHO stage were statistically significant (Table 4).

Table 4

Predictors of weight change among newly initiated ART clients in Dessie, July, 2020. ( $n=58$, ${ }^{a} T=6$ and number of Observations 322).

\begin{tabular}{|c|c|c|c|c|c|}
\hline \multirow{2}{*}{$\begin{array}{l}\text { Weight } \\
\text { Age }\end{array}$} & \multirow{2}{*}{$\begin{array}{l}\text { Coef. } \\
0.09\end{array}$} & \multirow{2}{*}{$\begin{array}{l}\text { Std. } \\
\text { Err. } \\
0.08\end{array}$} & \multirow{2}{*}{$\begin{array}{l}\begin{array}{l}P> \\
\text { value }\end{array} \\
0.261\end{array}$} & \multicolumn{2}{|c|}{$\begin{array}{l}\text { [95\% Conf. } \\
\text { Interval] }\end{array}$} \\
\hline & & & & -0.07 & 0.26 \\
\hline \multicolumn{6}{|l|}{ Sex } \\
\hline Male & 2.15 & 1.74 & 0.218 & -1.27 & 5.56 \\
\hline \multicolumn{6}{|l|}{ Disclosing HIV status } \\
\hline No & 0.76 & 1.31 & 0.562 & -1.81 & 3.33 \\
\hline \multicolumn{6}{|l|}{ Residence } \\
\hline Rural & -1.68 & 1.65 & 0.309 & -4.93 & 1.56 \\
\hline \multicolumn{6}{|l|}{ Opportunistic infection } \\
\hline No & 1.85 & 0.6 & $0.002 *$ & 0.66 & 3.03 \\
\hline $\begin{array}{l}\text { Interaction between months on ART and functional } \\
\text { status }\end{array}$ & -0.156 & 0.38 & 0.680 & -0.9 & 0.59 \\
\hline \multicolumn{6}{|l|}{ Tuberculosis } \\
\hline No & -3.12 & 2.09 & 0.135 & -7.21 & 0.97 \\
\hline Months on ART interact with WHO stage & 0.33 & 0.34 & 0.320 & -0.32 & 0.99 \\
\hline Months on ART interact with OI & 0.09 & 0.02 & $0.000 *$ & 0.05 & 0.13 \\
\hline \multicolumn{6}{|l|}{ Functional status } \\
\hline Ambulatory and Bedridden & -2.6 & 1.76 & 0.138 & -6.04 & 0.84 \\
\hline Months on ART interact with regimen change & -0.08 & 0.08 & 0.303 & -0.23 & 0.07 \\
\hline \multicolumn{6}{|l|}{ Taking Cotrimoxazole Preventive Therapy } \\
\hline Currently on not CPT & 0.16 & 0.2 & 0.421 & -0.23 & 0.56 \\
\hline \multicolumn{6}{|l|}{ WHO stage } \\
\hline Advanced Stage $^{a}$ & -3.52 & 1.62 & $0.030^{*}$ & -6.71 & -0.34 \\
\hline \multicolumn{6}{|l|}{ Educational status } \\
\hline Have formal Education & 2.26 & 1.75 & 0.196 & -5.69 & 1.17 \\
\hline \multicolumn{6}{|l|}{ Marital Status } \\
\hline Currently married & -2.27 & 1.76 & 0.198 & -5.72 & 1.18 \\
\hline
\end{tabular}


The interaction term of months on ART with the absence of opportunistic infection increases $0.09 \mathrm{~kg}$ of weight over time as a month on ART increases in adult ART clients. Adult ART clients with absence of opportunistic infection over a period of time in a month on ART increase their weight by $1.85 \mathrm{~kg}$ within the time span of their follow up. Adult ART clients, who were experienced advanced WHO stage disease over a period of their follow up time a month on ART, were decrease their weight by $3.5 \mathrm{~kg}$ in their follow-up time (Table 4).

\section{Discussion}

The weight of adult on ART clients a positive progressive change on their follow-ups. A positively changed weight shows an improvement in their condition compared with their baseline. Most of the ART clients come in the advanced stage of HIV AIDS diseases(14), so taking ART drug that slows the replication of the virus and boosting their immunity over period of times(3). In a study conducted in Arba Minch, Ethiopia a short duration of taking ART shows a lower body mass index(15). Another study also shows a significant increment of weight within one year(6) it shows that $2.7 \mathrm{~kg}$ increases on average within one year(6). Monitoring weight of the patient in every follow up visit should consider the progress of patients towards the compliances of Antiretroviral Therapy and clinical conditions.

The interaction term of months on ART with absence of opportunistic infection was found statistically significant over time has a contribution of positive weight gain through times in adult ART clients. Adult ART clients with the experience of opportunistic infection in their follow-up period show a decrease in their weight over a period of time(16). Another study suggests that a longer stayed on ART increase the risk of acquiring an opportunistic infection(17). So, considering the finding of this interaction effect to keep clients free from any opportunistic infection for the good progress of weights for clients under ART.

Adult ART clients with absence of opportunistic infection over a period of time and had a positive contribution to weight changes though times. Adult ART clients not experiencing any opportunistic infection over a period of time show an increment in their weight during their follow-up period. Weight loss is the most common symptom during diagnosis(18) and after initiation of ART(19). Clients facing weight loss from previous follow up is the sign of developing new opportunistic infection (20). Opportunistic infections remain a challenge in patients receiving ART in resource-limited settings(21), so keeping clients free from any opportunistic infection is good progress toward positive weight gain and improves their clinical stage of diseases.

Adult ART clients, who were experienced advanced WHO stage disease over a period of their follow up time, were negatively associated with weight gain in their follow-up time. Adult ART clients who experience an advanced stage of the disease is a decline in their weight(16). The WHO stage is categorized based on different criteria among these criteria, severe weight loss and wasting syndrome are the criteria found in stage 3 and stage four, respectively(12)(22). This evidence is supported in different studies conducted in Arba Minch and Jimma, Ethiopia in which adult ART clients with advanced WHO stage significantly associated with undernutrition, which was measured using body mass index $(15,23)$. A decline in the weight of Adult ART clients need crucial assessment on the stage of their diseases and therapy per the national guideline

\section{Limitation of the Study}

This study is not without limitation; 1) This study includes only patients' medical records with complete data, so this might have made a selection bias; 2) All the measurements documented in the chart were not sure about the calibration and consistency of measurements and also shares limitations of retrospective studies.

Page $11 / 17$ 


\section{Conclusion}

Adult ART clients gain weight $4.92 \mathrm{~kg}$ (C95\%: 3.03-6.82) within one year after the initiation of ART clients. Adult ART clients who experienced advanced stage of WHO diseases decrease their weight, whereas no opportunistic infection and its interaction with months on ART increase the weight of ART Clients.

\section{Declarations}

\section{Ethics Approval and Consent to Participate}

This study was approved by the Ethical Review Committee of Wollo University, College of Medicine and Health Science. A permission letter was also taken from Zonal Health Department and Respective Health Facilities as well all methods were performed under the Helsinki Declaration. Informed Consent of the participants' chart review, was waived by Quality Assurance Committee of the respective Health Facilities on behave of their clients.

\section{Consent for Publication}

Not applicable.

\section{Availability of Data and Materials}

The data set for this result and conclusion of the manuscript is available and contact the corresponding author on reasonable request.

\section{Competing Interests}

The authors declare no computing interest.

\section{Funding}

The source of funding is self-sponsored.

\section{Authors' Contributions}

All authors made a significant contribution to the work reported, whether that is in the conception, study design, execution, acquisition of data, analysis and interpretation, or in all these areas; took part in drafting, revising or critically reviewing the article; gave final approval of the version to be published; have agreed on the journal to which the article has been submitted; and agree to be accountable for all aspects of the work.

\section{Acknowledgement}


We acknowledge College of Health and Medicine and Health Science, Wollo University for its periodic follow-up and support. We also acknowledge Dessie City Zonal Health Department for providing access to the data and also our thanks go to the data collectors and supervisors for the carefully undertaking of their tasks.

\section{References}

1. Koethe JR, Heimburger DC. Nutritional aspects of HIV-associated wasting in sub-Saharan Africa 1-4. 2010;91:1138-42.

2. WHO. The use of antiretroviral drugs for treating and preventing hiv infection. 2016;

3. DHHS. Guidelines for the Prevention and Treatment of Opportunistic Infections in HIV-Infected Adults. 2018;

4. Amza L, Demissie T, Halala Y. Under nutrition and associated factors among adult on highly active antiretroviral therapy in Wolaita Sodo teaching and referral hospital, southern nation 's nationalities people 's region, Ethiopia. 2017;9(February):10-9.

5. FANTA. Nutrifion Assessment, Counselling and Support (NACS):Job Aids for Health Facility-Based Service Providers. 2016;

6. Yuh B, Tate J, Butt AA, Crothers K, Freiberg M, Leaf D, et al. Weight Change After Antiretroviral Therapy and Mortality. 2015;60:1852-9.

7. Raj P, Pandey A. Effects of Antiretroviral Therapy on the Survival of Human Immunodeficiency Virus-positive Adult Patients in Andhra Pradesh, India : A Retrospective Cohort Study, 2007-2013. 2016;394-405.

8. Negessie A, Jara D, Taddele M, Burrowes S. Determinants of undernutrition among adult patients receiving antiretroviral therapy at Debre Markos referral hospital, Northwest Ethiopia : a case-control study design. 2019;1-11.

9. Al, Hagazi Gebre Meles, Haftom Temesgen MA. CD4 Count Progression of Adult HIV Patients Under Art Follow Up At Mekelle General Hospital, Tigray Region : A Longitudinal Data Analysis Approach. 2019;16(4):1-11.

10. Caruana EJ, Roman M, Hernández-sánchez J, Solli P. Longitudinal studies. 2015;7(V):537-40.

11. Pepfar. Ethiopia Country Operational Plan COP2020/FY2021 Strategic Direction Summary. 2020;

12. EFMoH. NATIONAL CONSOLIDATED GUIDELINES FOR COMPREHENSIVE HIV PREVENTION, CARE AND. 2018;

13. Twisk JWR. Applied Longitudinal Data Analysis for Epidemiology. Second. 2013.

14. Moges NA, Adesina OA, Okunlola MA, Berhane Y. Same-day antiretroviral treatment (ART) initiation and associated factors among HIV positive people in Northwest Ethiopia: baseline characteristics of prospective cohort. Arch Public Heal. 2020;78(1):1-13.

15. Oumer B, Boti N, Hussen S, Gultie T. Prevalence of undernutrition and associated factors among adults receiving first-line antiretroviral treatment in public health facilities of Arba Minch Town, Southern Ethiopia. HIV/AIDS - Res Palliat Care. 2019;11:313-20.

16. Sood P, Bhandari C. To Study the Clinical Profile of Hiv/Aids Patients. Int J Med Biomed Stud. 2019;3(5):1425.

17. Weldegebreal T, Ahmed I, Muhiye A, Belete S, Bekele A. Magnitude of opportunistic diseases and their predictors among adult people living with HIV enrolled in care: national level cross sectional study, Ethiopia. 2018;1-11.

18. Chhatwani CM, Gagiya AK, Patel A, Raval R, Bhadiyadra V. Clinical Presentation of Newly Diagnosed Hiv Positive patients and their correlation with Cd4 count in Indian Scenario. 2016;15(6):87-91. 
19. Agrawal E, Pradhan S, Murthy R, Tomar R. Recent scenario of Opportunistic infection in HIV-infected individuals at a tertiary care hospital in Bilaspur (C. G .). 2017;3(1):7-10.

20. Bariha PK, Mohapatra MK, Kullu BK, Karua PC, Biswal SB, Thakur A. Prospective study of opportunistic infections among HIV infected patients in VSS Institute of Medical Science and Research, Burla, Sambalpur, Odisha, India. 2018;5(3):566-72.

21. Bhuvana KB, Hema NG, Patil RT. Prevalence and risk factors for opportunistic infections in HIV patients who developed adverse drug reactions (ADRs) to antiretroviral therapy ( ART ) in a tertiary-care teaching hospital. 2015;5(3):200-6.

22. Xie J, Hsieh E, Sun MQ, Wang HL, Lv W, Fan HW, et al. Delays in HIV diagnosis and associated factors among patients presenting with advanced disease at a tertiary care hospital in Beijing, China. PLoS One.

2017;12(8):1-11.

23. Yitbarek GY. Magnitude of obesity / overweight and its associated factors among HIV / AIDS patients on antiretroviral therapy in Jimma University Specialized and Teaching hospital, south west Ethiopia : Hospital based Crossectional study. :1-16.

\section{Figures}

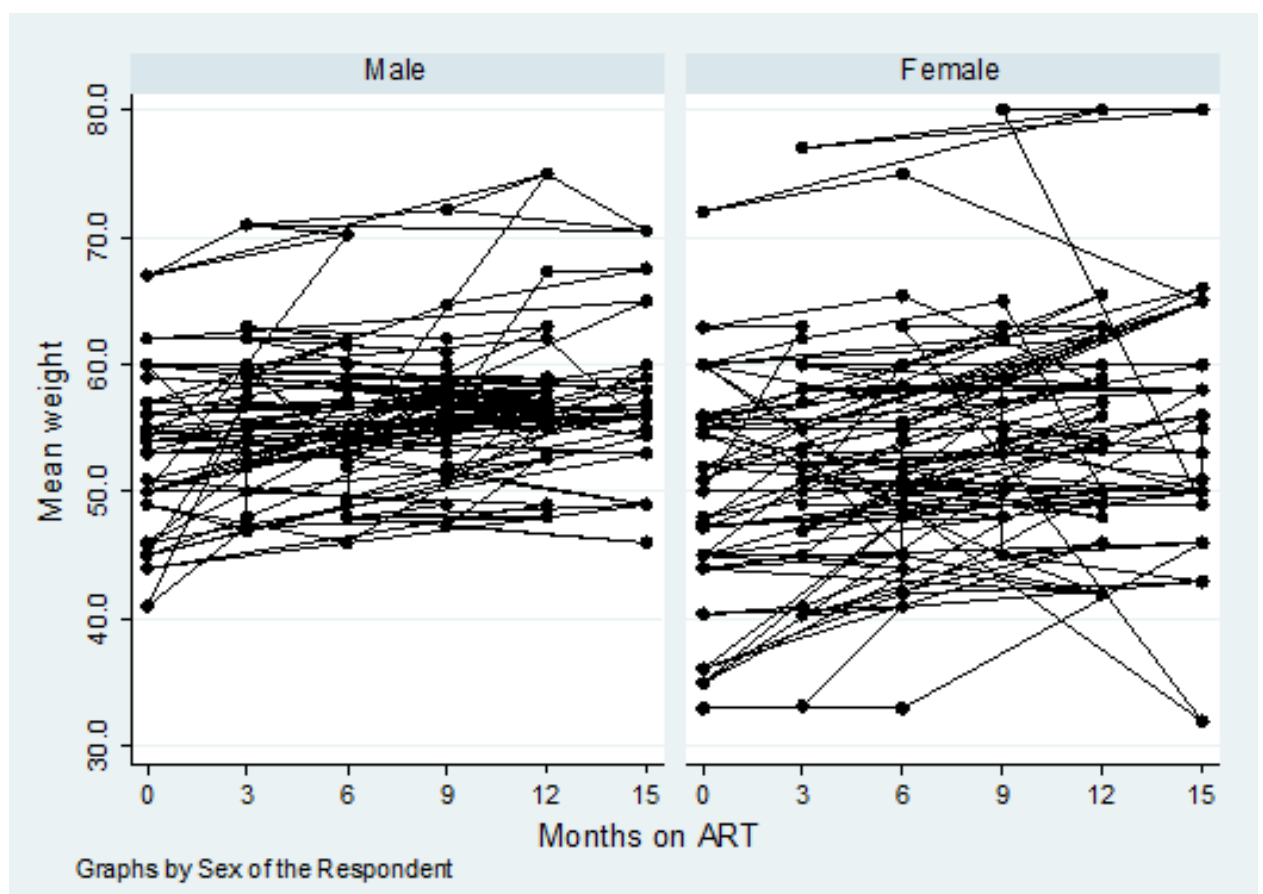

\section{Figure 1}

Individual Profile of Newly ART initiated ART Clients in Dessie City, July 2020. 


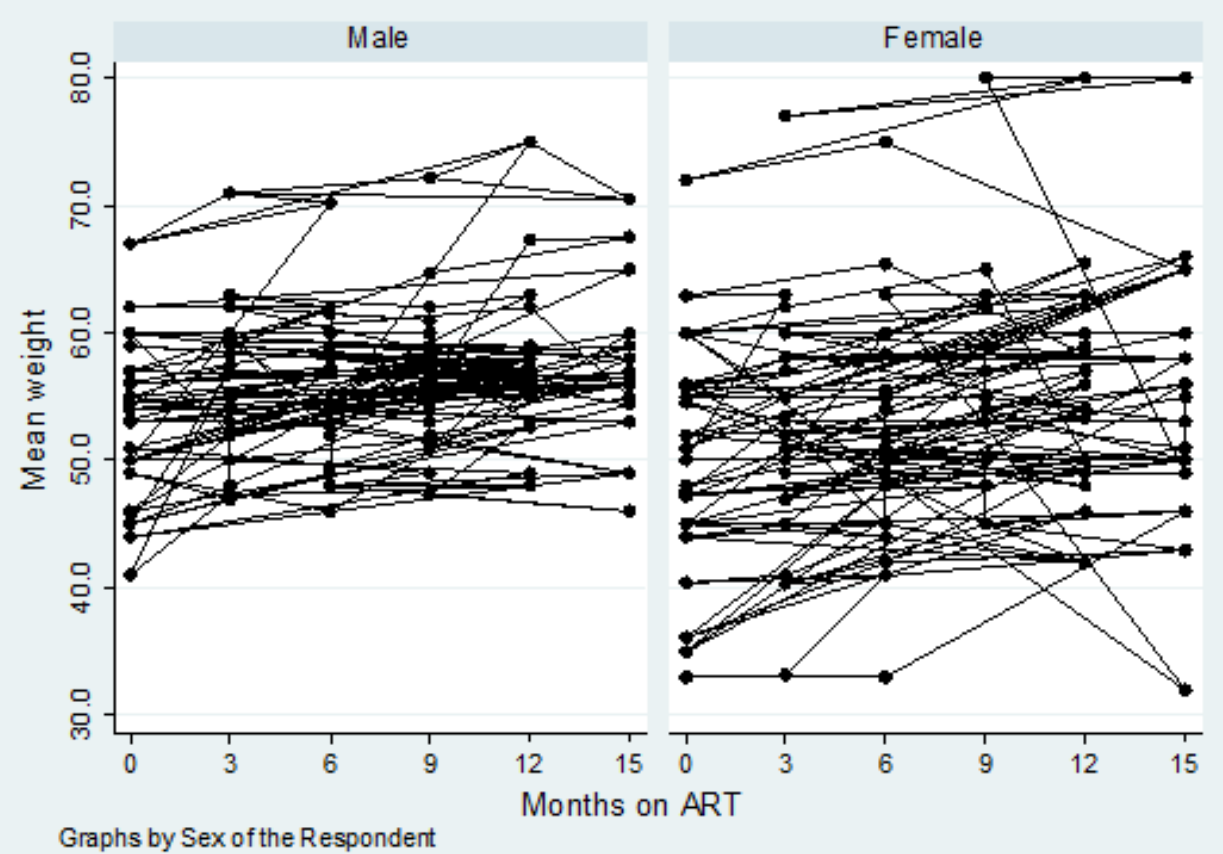

\section{Figure 1}

Individual Profile of Newly ART initiated ART Clients in Dessie City, July 2020.

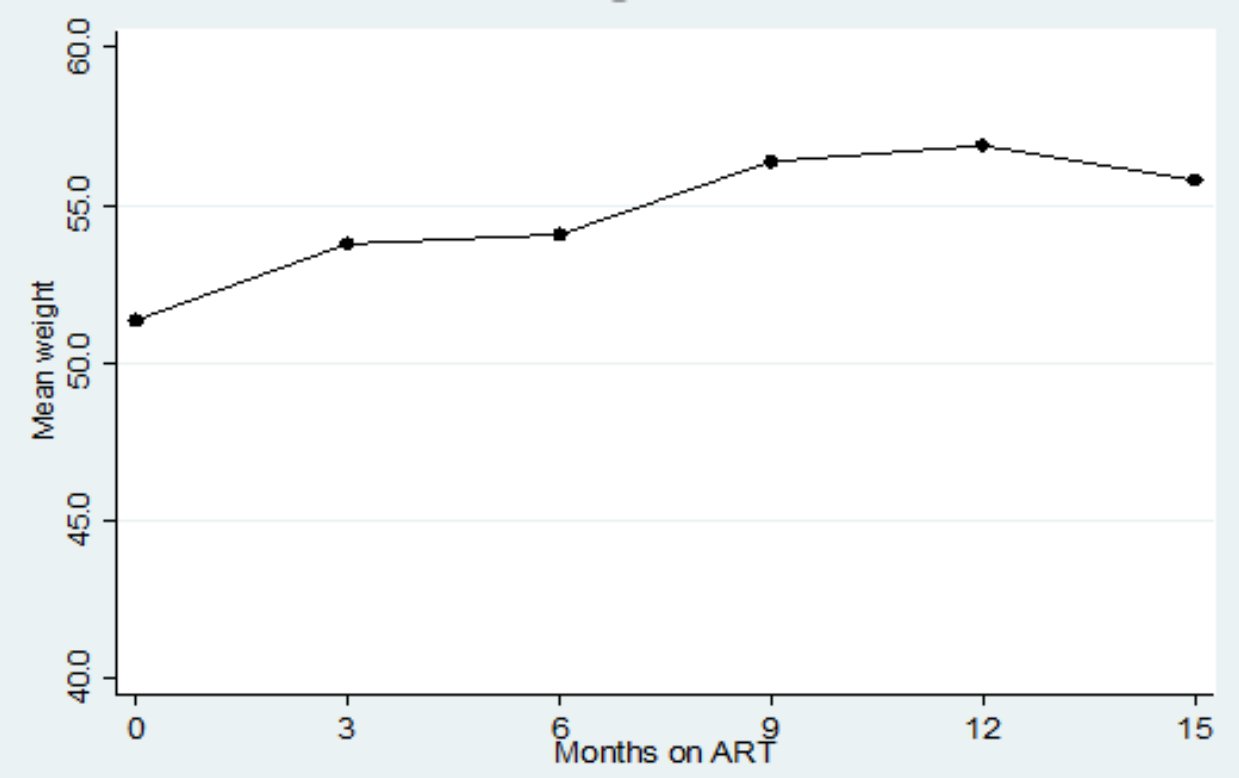

\section{Figure 2}

The mean Weight Change in Dessie City, July 2020. 


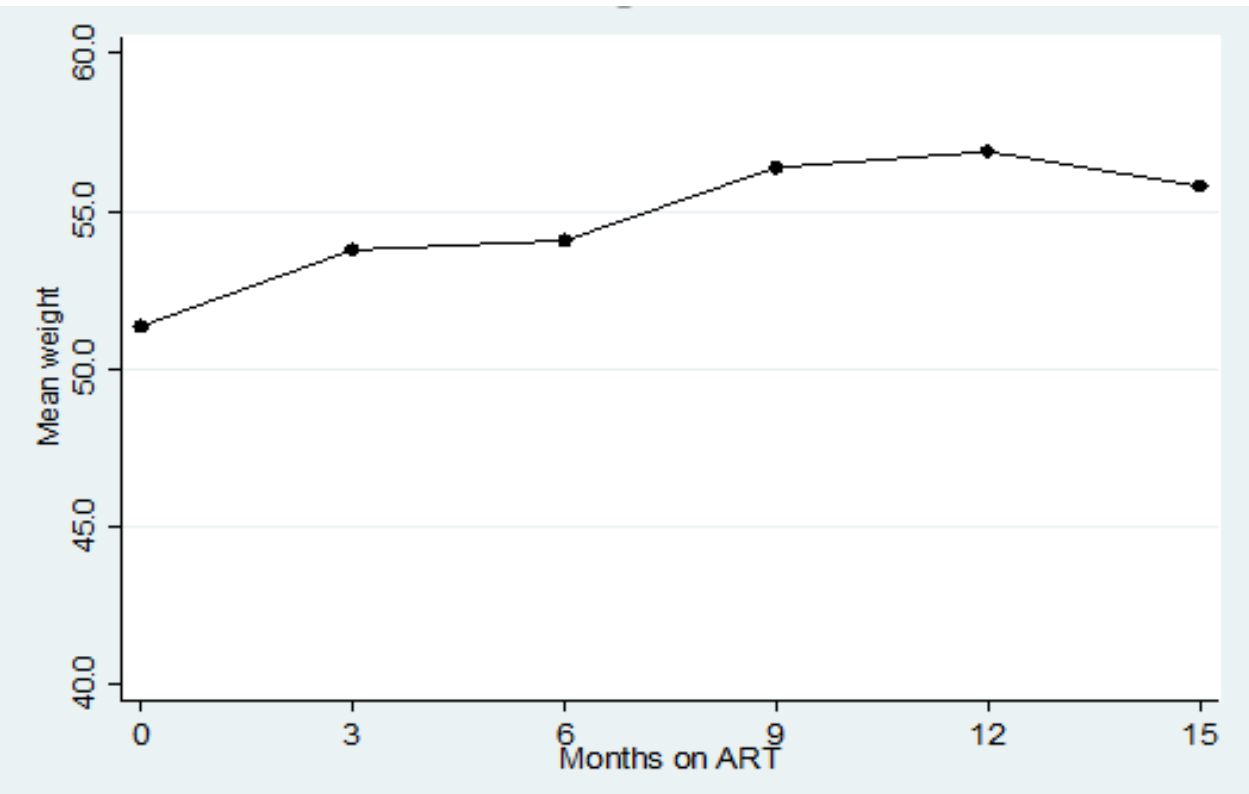

\section{Figure 2}

The mean Weight Change in Dessie City, July 2020.

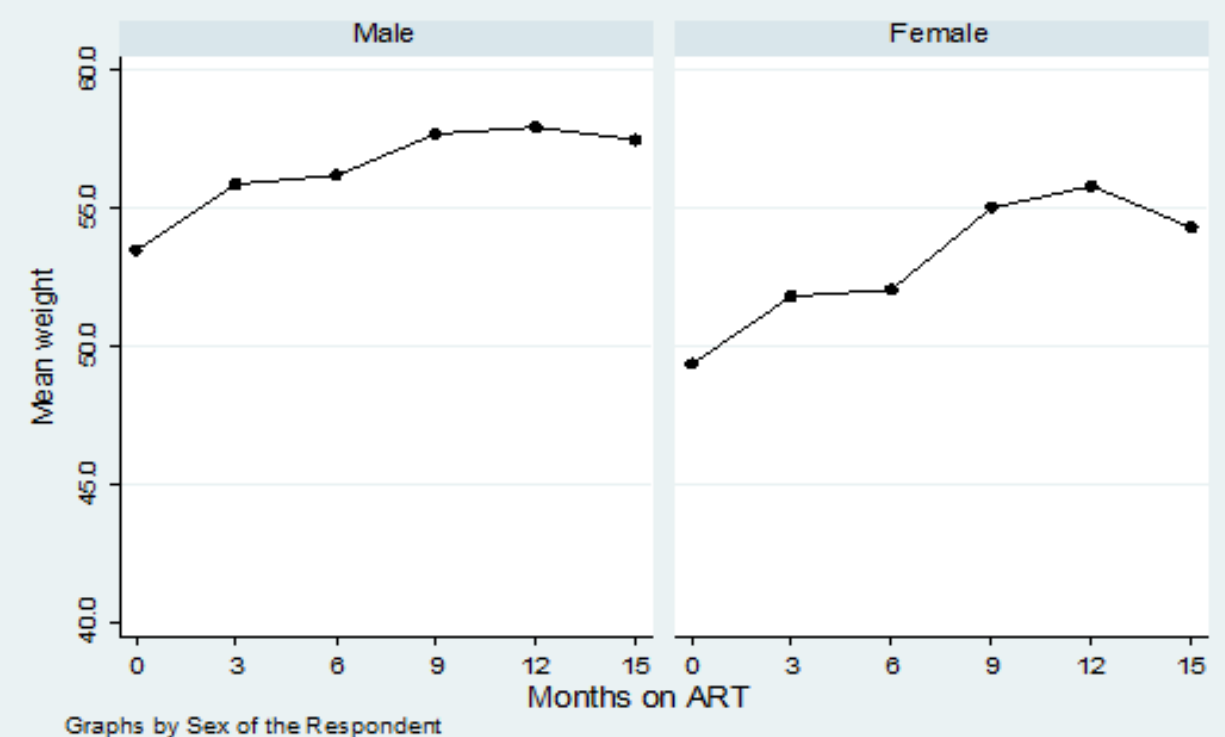

\section{Figure 3}

The mean weight in Male and Female in Dessie City, July 2020 


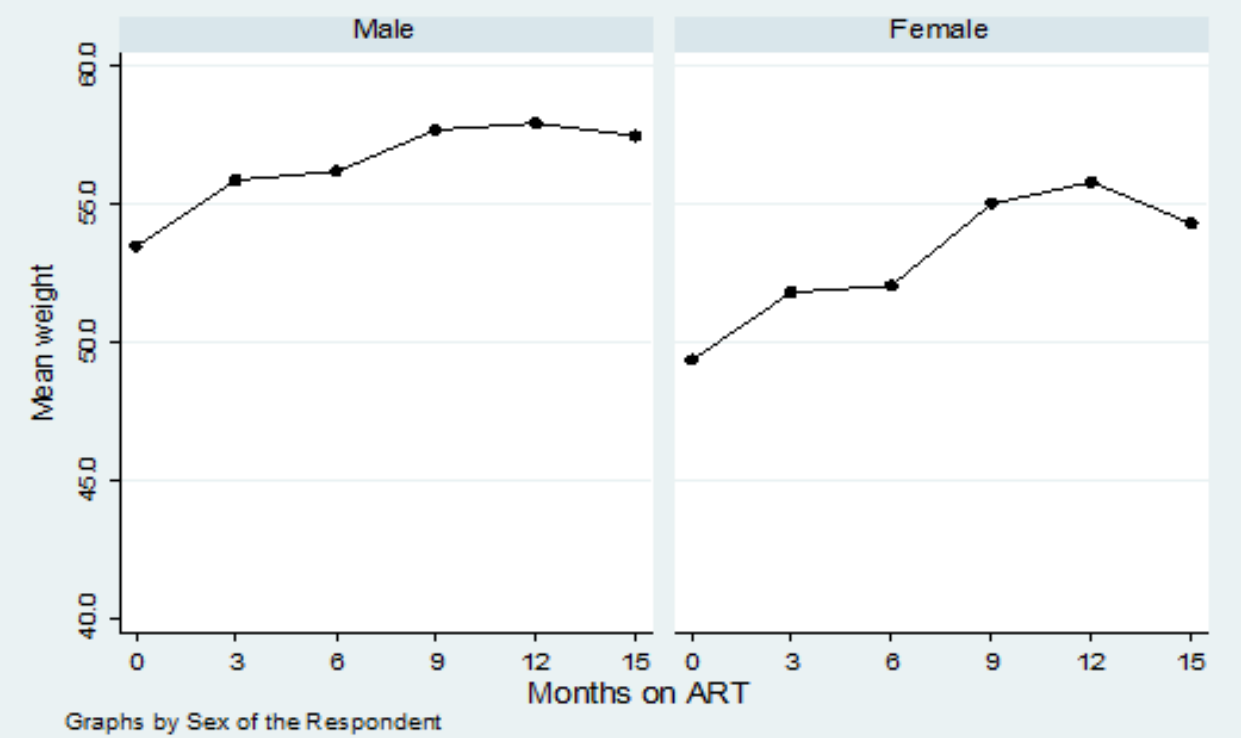

\section{Figure 3}

The mean weight in Male and Female in Dessie City, July 2020 